\title{
Effect of Ambient Temperature on PUF Passive Samplers and PAHs Distribution in Puerto Rico
}

\author{
Nedim Vardar ${ }^{1}$, Ziad Chemseddine ${ }^{1}$, Juan Santos ${ }^{2}$ \\ ${ }^{1}$ School of Engineering, Inter American University, Bayamon, PR, 00957 \\ ${ }^{2}$ Department of Natural Science, Inter American University, Bayamon, PR, 00957 \\ Email: nvardar@bayamon.inter.edu
}

Received 2013

\begin{abstract}
Passive sampling for the monitoring of organic pollutants (PAHs, PCBs, PBDEs) in ambient air has received increased attention in the last two decades. However, the accuracy of the concentration of organics obtained with passive samplers under varying environmental conditions is a subject of controversy. In this study, effect of ambient temperature on passive samplers was evaluated by using three different sampler configurations. Additionally, passive samplers with polyurethane disks (PUF) were applied throughout the Island for the determination of the airborne concentration of polycyclic aromatic hydrocarbons (PAHs). The passive samplers were deployed in seven municipalities for three-month periods in two different sampling campaigns, representing hurricane and non-hurricane seasons. Here we present preliminary results obtained from those sampling campaigns. The total concentrations of 15 PAHs varied from 3.1 to 19.6 and from 5.5 to $38.5 \mathrm{ng} / \mathrm{m}^{3}$ for hurricane and non-hurricane seasons, respectively. Hurricane and non-hurricane season concentrations of PAH were significantly different for the samples taken in the northern municipalities of the Island. However, there was no significant difference in PAH concentrations between the hurricane and non-hurricane seasons for the southern sites. Increased rainfall and high-relative humidity during the hurricane season had an influence on the concentrations of PAHs derived by the passive PUF sampler.
\end{abstract}

Keywords: Passive Sampler; PAH; Puerto Rico; Hurricane; PUF; Ambient Temperature

\section{Introduction}

Passive samplers with polyurethane disks (PUF) have been widely used for the last decade in the measurement of semi volatile organics (SOCs), in part because they are easy to handle, operate independently for several months, and are inexpensive. Knowledge of the sampling rate of the device is necessary for an accurate conversion of the sampled mass to an ambient concentration. However, environmental conditions around the sampler influence the sampling rate and the performance with which the PUF sampler can be used. The reliability of passive sampling techniques under varying environmental conditions is therefore a subject of controversy. Environmental conditions that may affect the PUF sampler are wind speed, temperature $(\mathrm{T})$, atmospheric pressure, sunlight/UV-light and humidity. T affects the compound specific molecular diffusion coefficients (D) of the pollutants by increasing $\mathrm{D}$ with $\mathrm{T}$.

Polycyclic aromatic hydrocarbons (PAHs) are a natural component of most fossil fuels, and formed during the incomplete combustion of these fuels, or other organic substances. Some PAHs are manufactured as individual compounds for research purposes. The chemical structure of PAHs is comprised of two or more fused aromatic rings made entirely from carbon and hydrogen. PAHs are ubiquitous environmental pollutants and are formed from both natural and anthropogenic sources. Although natural sources such as forest fires and volcanic eruptions contribute to PAH formation, most PAHs in ambient air are the result of man-made processes. PAHs pose severe risks to human health and the environment due to their toxicity, persistence, ability to travel long distances on air and water currents [1-3]. Human exposure to these compounds may result in a variety of adverse health effects including damage to the central nervous and reproductive systems, development of lung cancer and genetic alterations. There are hundreds of PAH compounds in the environment, but only 16 of them are included in the priority pollutants list of the U.S. environment protection agency (USEPA) [4].

A number of studies have been conducted on the fate of PAHs in atmosphere during the past three decades [1-3, 5-9]. In most of these studies, a high-volume sampling technique using filter and adsorbent has been applied. However, the use of passive sampling methods to moni- tor airborne contaminants has greatly increased 
over the past few years. Passive samplers can be deployed at loca- tions where it is difficult or impractical to install and maintain Hi-Vol samplers. These devices are simple and inexpensive and do not need field calibration, electricity nor technical personnel at the sampling site. In addition, they can be deployed in many locations concurrently due to their low cost.

Puerto Rico is located in the Caribbean with mainly north-easterly trade winds. Due to its location, the Island enjoys a tropical climate and also experiences the Atlantic hurricane season. In this study, effect of ambient temperature on passive samplers and seasonal distribution of PAHs were evaluated Characterization of the PAHs in the ambient air has been studied for a long time in other parts of the world. A vast number of publications are available in the literature for both urban and rural areas from developed and developing countries [1-3,5-7]. How-ever, only limited data on atmospheric PAHs had been acquired for Puerto Rico, and to our knowledge, this is the first study to compare $\mathrm{PAH}$ concentrations spatially distributed across the island.

\section{Materials and Method}

\subsection{Sampling Locations}

Puerto Rico is a tropical island located in the Caribbean Sea with a population of around 4 million. It has 9100 $\mathrm{km}^{2}$ total area and is one of the most densely populated islands in the world. PUF passive air samplers consisting of polyurethane foam disks of $14 \mathrm{~cm}$ diameter and 1.2 cm thickness housed in two stainless steel bowls were deployed in Bayamon, Cayey, Carolina, Guayama, Manati, San Sebastian, and Naguabo (Figure 1).

Two sampling campaigns were achieved in 2010 for three-month periods except in Naguabo where sampling took place for six motnhs. Sampling parameters for the samples are summarized in Table 1. Sampling sites of Cayey and Manati are considered as urban, medium density, and residential. Bayamon and Carolina is described as urban, high-density residential/industrial area. Naguabo site is characterized as low-density coastal/residential. San Sebastian is located in west part of the Island and

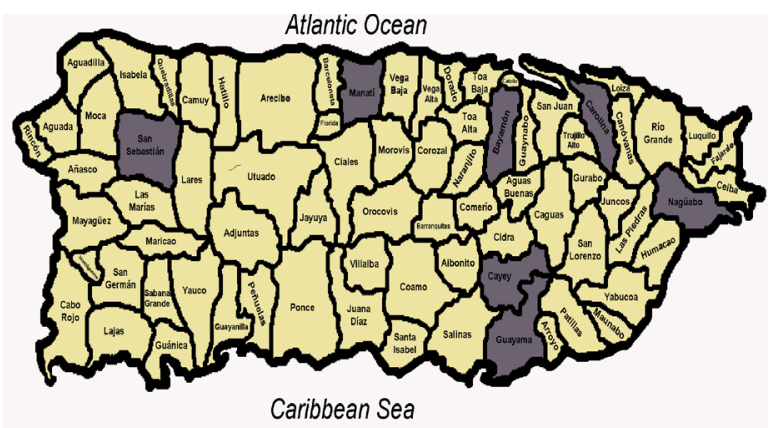

Figure 1. Map of Puerto Rico showing sampling locations.
Table 1. Passive Sampling Campaign Parameters.

\begin{tabular}{ccccc}
\hline $\begin{array}{c}\text { Sampling } \\
\text { Campaign }\end{array}$ & $\begin{array}{c}\text { Start } \\
\text { Date }\end{array}$ & $\begin{array}{c}\text { End } \\
\text { Date }\end{array}$ & $\begin{array}{c}\text { Temp. } \\
\left({ }^{\circ} \mathbf{C}\right)\end{array}$ & $\begin{array}{c}\text { Rain } \\
(\mathbf{c m})\end{array}$ \\
\hline $\begin{array}{c}\text { Non-Hurricane } \\
\text { Season }\end{array}$ & March 2010 & June 2010 & 27.7 & 17.9 \\
Hurricane Season & June 2010 & October 2010 & 28.6 & 21.8 \\
\hline
\end{tabular}

considered as urban, medium density, and residential. Last, Guayama sampling site is situated in a coastal/rural region.

The temperature in the south of the Island is usually a few degrees higher than the north. Between winter and summer, there is only a temperature swing of around $3^{\circ} \mathrm{C}$ Rainfall tends to be evenly distributed throughout the year, but doubles during the months from May to October, as falls from November to April, with a driest period from January to April. The wind patterns across the island are basically zonal, from east to west.

\subsection{Analytical Procedures}

Information for sample preparation, extraction and analysis is given in detail elsewhere [8]. Briefly, each PUF was Soxhlet extracted with a 20:80 dichloromethane (DCM): petroleum ether (PE) solution for $24 \mathrm{~h}$. All samples were spiked with PAHs surrogate standards prior to extraction. Four deuterated PAHs were used as surrogate standard and Pyrene- $\mathrm{d}_{10}$ for volumetric corrections. The recoveries of the following surrogate standards were used to correct the amounts of specific PAHs found in the samples: Acenaphthene- $\mathrm{d}_{10}$ for acenaphthene (ACE), acenaphthylene (ACT) and fluorine (FLN), phenanthrene- $\mathrm{d}_{10}$ for phenanthrene (PHE), anthracene (ANT), and fluoranthene (FL), chrysene- $d_{12}$ for pyrene (PY), benz(a) anthracene (BaA) and chrysene (CHR), and perylene- $\mathrm{d}_{12}$ for benzo (b) fluoranthe $(\mathrm{BbF})$, benzo(k)fluoranthe $(\mathrm{BkF})$, benzo (a) pyrene (BaP), indeno (1,2cd) pyrene (IcdP), dibenz (a,h) anthracene (DahA), and benzo(ghi)perylene (BghiP). The average recoveries for surrogates in field samples were $79 \% \pm 31 \%$ for acenaphthene- $\mathrm{d}_{10}, 86 \% \pm 13 \%$ for phenanthrene- $\mathrm{d}_{10}, 84 \% \pm 28 \%$ for chrysene- $\mathrm{d}_{12}, 80 \% \pm 15 \%$ for perylene- $\mathrm{d}_{12}$.

The analysis of the samples was performed using a Varian 450-GC coupled to an ion trap mass spectrometer Varian 240 MS. A Varian factor 4 capillary column (30 $\mathrm{m}, 0.25 \mathrm{~mm}, 0.25 \mu \mathrm{m}$ ) was used. The GC oven temperature was programmed from $60^{\circ} \mathrm{C}$ (held one minute) to $130^{\circ} \mathrm{C}$ at $7^{\circ} \mathrm{C} \min ^{-1}$, then raised to $200^{\circ} \mathrm{C}$ at $5^{\circ} \mathrm{C} \mathrm{min}^{-1}$, and finally increased from $260^{\circ} \mathrm{C}$ to $320^{\circ} \mathrm{C}$ at $6^{\circ} \mathrm{C} \mathrm{min}^{-1}$. The injector temperature was maintained at $295^{\circ} \mathrm{C}$. The linearity in the response of the GC/MS system was evaluated with calibration standards, at five different levels of concentration $(0.012,0.06,0.3,0.6$ and $1.2 \mathrm{ng} / \mathrm{mL})$. The instrument was Auto tuned at the start of runs with 
perfluorotributylamine (PFTBA). Individual PAHs were identified based on the retention times of target ion peaks. Internal standard calibration procedure was used for quantifying the identified compounds.

Field blanks, which accompanied samples to the sampling site, were used to determine any contamination during sample handling and preparation. Newly cleaned PUFs were used as laboratory blanks. There was no statistically recognizable difference between field and laboratory blanks.

\section{Results and Discussions}

Passive sampling devices have been widely used for more than a decade for the measurement of semi volatile organics (SOCs) in air. PUF passive air sampler consists of two stainless steel bowls and all parts of the sampler are made from the stainless steel. In this study, twenty four hour temperature changes inside the passive sampler were characterized using $\mathrm{HOBO}$ pendant temperature sensor. In addition to stainless steel sampler, two more samplers, one consists of plastic bowls and another with cupper bowls, were used to characterize the effect material on the diurnal temperature changes inside the samplers. Figure 2 shows the diurnal temperature changes inside a stainless steel sampler. Temperature variation inside and outside the sampler is shown with blue and green lines, respectively. Temperatures inside the sampler were significantly higher than outside temperatures during the midday due to intense solar radiation. During the early mornings and late afternoon hours no significant temperature differences were observed between inside and outside of the sampler.
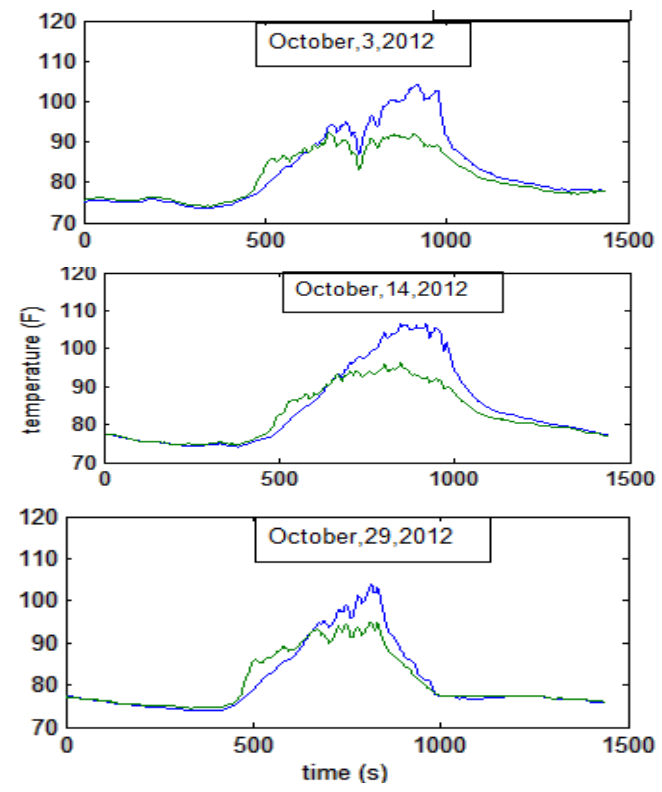

Figure 2. Temperature variation inside (blue line) and outside (green line) of a stainless steel sampler.
In order to minimize midday temperature differences between inside and outside of the sampler, choices of other feasible materials were investigated. Cupper and plastic sampling bowls were used in constructing the passive sampler. Figure $\mathbf{3}$ compares the diurnal temperature changes among different samplers. It was expected that the lowest temperature would be observed inside the plastic passive sampler due to the lower conductivity of plastic. However, as it can be seen from the Figure 3, the highest temperature inside the samplers belongs to the one made of plastic bowls. A further study is needed to explain this finding. Out of these three samplers, stainless steel sampler gave the lowest internal temperatures.

A network of passive sampling spatially distributed throughout Puerto Rico including both urban and rural areas were conducted. The present study presents the first ambient air data for PAHs in Puerto Rico. Due to its location, Puerto Rico enjoys a tropical climate and also experiences the Atlantic hurricane season. Hurricane season extends from June $1^{\text {st }}$ to November $30^{\text {th }}$. Therefore, samples taken in the first and second sampling campaign were classified as non-hurricane and hurricane samples, respectively. Higher PAH concentrations were obtained in all sampling sites for the non-hurricane samples except Cayey site. The total concentrations of 15 PAHs varied from 3.1 to 19.6 and from 5.5 to $38.5 \mathrm{ng} / \mathrm{m}^{3}$ for hurricane and non-hurricane seasons, respectively (Figure 4).

Increased rainfall and high water vapor content during the hurricane season makes wet deposition very efficient, leading to a decreased atmospheric lifetime of PAHs for the Island. Carolina site had the highest PAH concentrations for both hurricane and non-hurricane season. Seasonal concentration differences of PAH were more significant for the samples taken in the northern municipalities (Bayamon, Manati, Carolina) than the southern municipalities (Cayey and Guayama) of the Island. The north

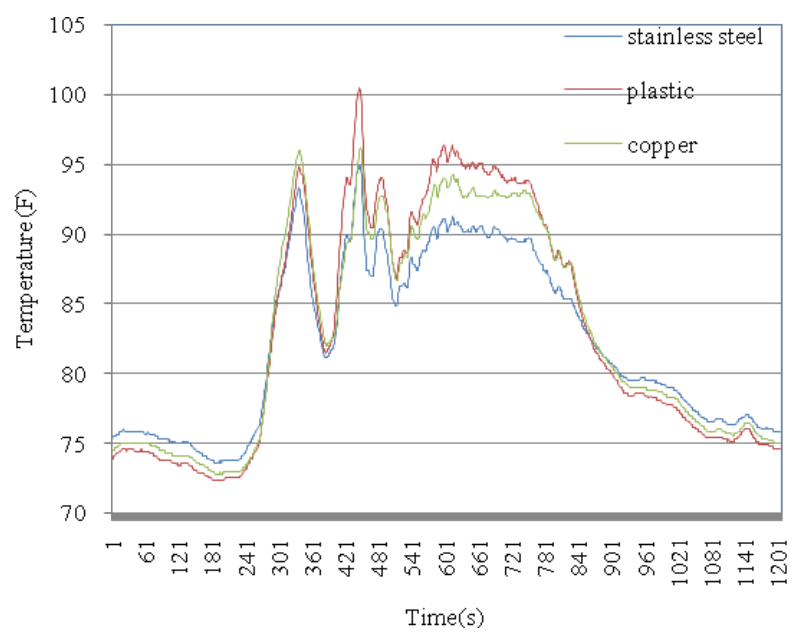

Figure 3. Diurnal temperature changes among different samplers. 


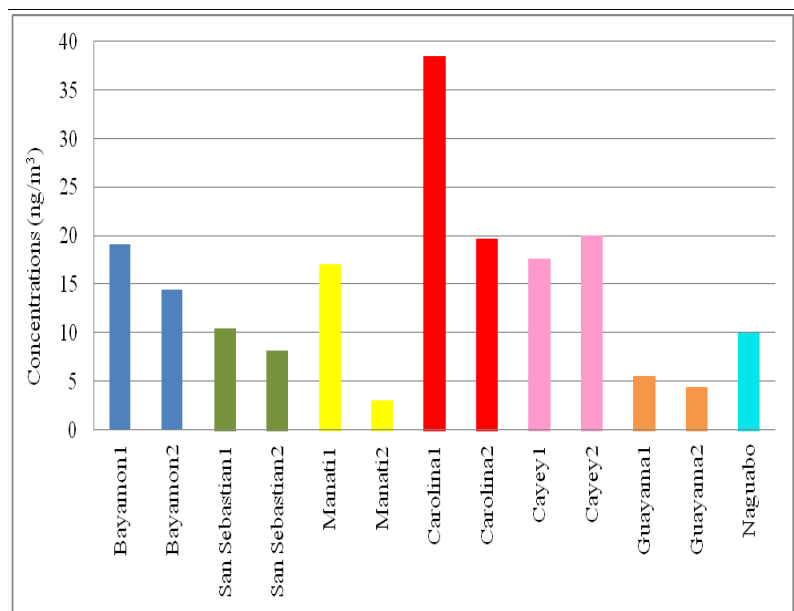

Figure 4. Total PAH concentrations for each sampling locations.

Table 2. Atmospheric PAH Concentrations Derived by Passive Samplers in Different Studies.

\begin{tabular}{lcc}
\hline \multicolumn{1}{c}{ Location } & $\begin{array}{c}\text { Range of Total } \\
\left.\text { PAHs (ng/ } \mathbf{m}^{3}\right)\end{array}$ & Reference \\
\hline $\begin{array}{l}\text { Various Municipalities, PR } \\
\text { Non-Hurricane Season }\end{array}$ & $5.5-38.5$ & This study \\
Hurricane Season & $3.1-19.6$ & \\
Toronto, Canada & & \\
Summer & $16.5-61.4$ & \\
Winter & $10.1-18.5$ & \\
Spring & $3.53-18.8$ & \\
Harbin, China & & \\
Spring & $25-120$ & \\
Summer & $13-50$ & [3] \\
Autumn & $22-74$ & \\
Winter & $81-240$ & \\
Taichung, Taiwan & 387.70 & [5] \\
Mexico City, Mexico & $32-92$ & [6] \\
Athens, Philippines & 28.44 & [7] \\
\hline
\end{tabular}

coast of the Island gets twice as much rain as the south coast. Thus, increased precipitation as well as high- relative humidity during might have an influence on the concentrations of PAHs derived by the passive PUF sampler.

Table 2 provides a comparison of the ambient PAH concentrations measured by passive samplers in different part of the world. The PAH concentrations in the Island are almost similar to those reported by [4] for winter and spring seasons, but compared to summer season the Island concentrations are lower.

The PAH levels reported for Taichung, Taiwan are an order of magnitude higher than those measured in this study $[14,15]$. In Mexico, and Harpin, China, PAH concentrations significantly higher than the one measured in this study [16]. In a study conducted in Athens, Philip- pines, PAH concentrations were approximately twice higher than those measured in this study [17].

\section{Conclusions}

This study has provided some baseline data on the atmospheric PAH levels in Puerto Rico which could be useful for establishing long-term atmospheric monitoring program in the Island. In this study, the spatial characteristics of PAHs derived from PUF passive sampler were studied for two different sampling campaigns at the seven different sampling sites of the Island. It was found that hurricane and non-hurricane season concentrations of $\mathrm{PAH}$ were significantly different for the samples taken in the northern municipalities of the Island. However, there was no significant difference in PAH concentrations between the hurricane and non-hurricane seasons for the southern sites. Increased precipitation and high-relative humidity during the hurricane season might have an influence on the concentrations of PAHs derived by the passive PUF sampler.

Diurnal temperature variations inside the passive samplers constructed from stainless steel, cupper and plastic sampling bowls were investigated. Sampler made of stainless steel gave the lowest internal temperatures.

\section{Acknowledgements}

The authors would like to tank to the NSF-MRI program for funding the purchase of the GC/MS/MS and to Puerto Rico Louis Stokes Alliance for Minority Participation (PR-LSAMP) for supporting this study.

\section{REFERENCES}

[1] A. Motelay-Massei, T. Harner, M. Shoeib, M. Diamond, G. Stern and B. Rosenberg, "Using Passive Air Samplers to Assess Urban-Rural Trends for Persistent Organic Pollut- ants and Polycyclic Aromatic Hydrocarbons. 2. Seasonal Trends for PAHs, PCBs, and Organochlorine Pesticides,” Environmental Science and Technology, Vol. 39, 2005, pp. 5763-5773. doi:10.1021/es0504183

[2] F. M. Jaward, N. J Farrar, T. Harner, A. J. Sweetmanand and K.C.Jones, Environment Sciencean Technoogy, Vol. 38, No. 1, 2004, pp. 34-41. doi:10.1021/es034705n

[3] P. Bohlin, K. Jones, H. Tovalin and B. Strandberg, “Observations on Persistent Organic Pollutants in Indoor and Outdoor Air Using Passive Polyurethane Foam Samplers. Atmospheric Environment, Vol.42, No. 31, 2008, pp. 7234-7241.doi:10.1016/j.atmosenv.2008.07.012

[4] USEPA, Provisional Guidance for Quantitative Risk Assessment of Polycyclic Aromatic Hydrocarbons, EPA/600/ R-93/089, US Environmental Protection Agency, Office of Research and Development, Washington, DC, 1993.

[5] G. C. Fang, Y. S. Wu, M. H. Chen, T. T. Ho, S. H. Huang 
and J. Y. Rau, "Polycyclic Aromatic Hydrocarbons Study in Taichung, Taiwan, during 2002-2003," Atmospheric Environment, Vol. 38, 2004, pp. 3385-3391. doi:10.1016/j.atmosenv.2004.03.036

[6] M. E. Bartkow, K. Booij, K. E. Kennedy, J. F. Muller and D. W. Hawker, "Passive Air Sampling Theory for Semivolatile Organic Compounds,” Chemosphere, Vol. 60, 2005, pp. 170-176. doi:10.1016/j.chemosphere.2004.12.033

[7] E. Santiago and M. Cayetano, "Polycyclic Aromatic Hydrocarbons in Ambient Air in the Philippines Derived from Passive Sampler with Polyurethane Foam Disk,"
Atmospheric Environment, Vol. 41, No. 19, 2007, pp. 4138-4147.doi:10.1016/j.atmosenv.2007.01.021

[8] N. Vardar, F. Esen and Y. Tasdemir, "Seasonal Concentrations and Partitioning of PAHs in a Suburban Site of Bursa, Turkey,” Environmental Pollution, Vol. 155, 2008, pp. 298-307. doi:10.1016/j.envpol.2007.11.026

[9] T. Gouin, L. Jantunen, T. Harner, P. Blanchard and T. Bidleman, "Spatial and Temporal Trends of Chiral Organochlorine Signatures in Great Lakes Air Using Passive Air Samplers," Environmental Science and Technology, Vol. 41, 2007, pp. 3877-3883. doi:10.1021/es063015r 